\title{
Give me a challenge or give me a raise
}

\author{
Aleksandr Alekseev ${ }^{1}$ (D) \\ Received: 12 February 2020 / Revised: 8 March 2021 / Accepted: 12 March 2021 / \\ Published online: 27 March 2021 \\ (c) The Author(s) 2021
}

\begin{abstract}
I study the effect of task difficulty on workers' effort. I find that task difficulty has an inverse-U effect on effort and that this effect is quantitatively large, especially when compared to the effect of conditional monetary rewards. Difficulty acts as a mediator of monetary rewards: conditional rewards are most effective at the intermediate or high levels of difficulty. The inverse-U pattern of effort response to difficulty is inconsistent with many popular models in the literature, including the Expected Utility models with the additively separable cost of effort. I propose an alternative mechanism for the observed behavior based on non-linear probability weighting. I structurally estimate the proposed model and find that it successfully captures the behavioral patterns observed in the data. I discuss the implications of my findings for the design of optimal incentive schemes for workers and for the models of effort provision.
\end{abstract}

Keywords Incentives $\cdot$ Task difficulty $\cdot$ Monetary rewards $\cdot$ Effort provision · Probability weighting

JEL Classification C91 $\cdot$ D91 $\cdot$ D81 $\cdot$ J20 $\cdot$ J33

\begin{abstract}
I thank my doctoral advisors: Jim Cox, Glenn Harrison, Vjollca Sadiraj, and Todd Swarthout for their continuous support and advice in developing this project. I thank the Editor (John Duffy) and anonymous reviewers whose detailed suggestions helped significantly improve the quality of the paper. I thank Klajdi Bregu, Sherry Gao, Joaquín Gómez-Miñambres, Susan Laury, Tom Mroz, Jean Paul Rabanal, and David Rojo-Arjona for their helpful comments on the earlier drafts of this paper. I thank conference participants at the ICES Conference on Behavioral and Experimental Economics (2015), the Southern Economic Association meetings (2015), the Economic Science Association meetings (2017) and seminar participants at Georgia State University, George Mason University, and European University at St. Petersburg for their valuable feedback. I also thank my interviewers at the Allied Social Science Associations meetings (2018) for stimulating discussions. Financial support from the Center for the Economic Analysis of Risk at Georgia State University is gratefully acknowledged. All remaining errors are my own. The data and replication code are available at https://github.com/aalexee/give_me_challenge
\end{abstract}

Aleksandr Alekseev

aleksandr.alekseev@ur.de

1 Department of Economics, University of Regensburg, Universitätsstr. 31, 93040 Regensburg, Germany 


\section{Introduction}

Labor economics has long recognized the role of monetary incentives in determining workers' effort (Lazear 2018). The effectiveness of monetary incentives that are tied to performance is well established. Behavioral economics added new insights to the effect of these conditional rewards by showing that their effectiveness is subject to psychological factors, such as crowding out of intrinsic motivation (Gneezy and Rustichini 2000) and choking-under-pressure (Ariely et al. 2009; Hickman and Metz 2015). ${ }^{1}$ This literature also discovered alternative incentive mechanisms, often inspired by studies in psychology, that can boost workers' effort at no extra monetary cost. Among such mechanisms are goal-setting (Gómez-Miñambres 2012; Corgnet et al. 2015, 2018), performance ranking (Blanes i Vidal and Nossol 2011), and framing (Hossain and List 2012). A recent World Bank Report highlights behavioral mechanisms as an important incentive tool in developing countries (World Bank Group 2015).

Despite the convergence of economic and psychological insights on the determinants of effort, an important strand of psychological literature remains untapped by economists. A psychological theory of motivation called motivational intensity theory posits that the primary determinant of effort is task difficulty (Brehm and Self 1989; Wright 1996). Task difficulty can be defined as a characteristic of a task that, when increased, reduces the probability of success in the task for any given level of effort. $^{2}$ Task difficulty is conceptually different from the cost of effort, even though the two concepts are sometimes mixed in the literature (Bremzen et al. 2015). ${ }^{3}$ I attempt to close this gap by proposing a theoretical mechanism behind the effect of task difficulty on effort and by causally testing this mechanism in an incentivized experiment.

Motivational intensity theory assumes that effort investment in completing a task is determined by the motivation to avoid wasting energy. This implies that effort is determined by the minimum amount of work needed to complete a task, as long as success seems possible and beneficial (Wright 1996; Brehm and Self 1989). ${ }^{4}$ The main prediction of the theory, which follows directly from its main assumption, is that effort increases with task difficulty up to a certain point. A further increase in difficulty causes effort to drop leading to an inverse-U pattern of effort response.

\footnotetext{
1 See Gneezy et al. (2011) for an excellent overview of the cases when monetary rewards do and do not work.

${ }^{2}$ Equivalently, achieving a given probability of success in a difficult task requires more effort than in an easy task. This is the most basic definition of difficulty and is nothing more than a slightly modified dictionary definition. Also, see Ely and Szydlowski (2020) for a similar approach to defining difficulty.

${ }^{3}$ Cost of effort is disutility from exerting effort and depends both on the task and preferences of an individual, whereas difficulty is a characteristic of a task. Low difficulty does not imply low disutility: it might be easy to wash dirty plates, but few people would find it pleasant!

4 Motivational intensity theory is not a formal model and its predictions, unlike those of economic models, are not derived from any utility maximization. The proposed relationship between effort and the minimum amount of work can, in fact, be viewed as the theory itself. All of the predictions of the theory follow trivially from this relationship. One of the goals of the present paper is to derive the predicted effect of difficulty on effort from the basic economic principles.
} 
Motivational intensity theory views monetary rewards as a mediating factor in effort provision that determines the point at which effort as a function of difficulty starts to drop.

Empirical studies in psychology provide extensive evidence for the inverse- $U$ relationship between task difficulty and effort in the context of a direct effect of difficulty on effort (Smith et al. 1990; Richter et al. 2008; Richter 2015), as well as the effect of difficulty on effort interacted with other factors, such as learning and ability (Brouwer et al. 2014; Latham et al. 2008), mood and fatigue (Brinkmann and Gendolla 2008; LaGory et al. 2011; Silvestrini and Gendolla 2009, 2011), motivation (Capa et al. 2008; Gendolla and Richter 2005; Gendolla et al. 2008), and anticipated difficulty (Wright 1984; Wright et al. 1986). ${ }^{5}$ Task difficulty has also been proposed as an important factor in activating analytical reasoning (Alter et al. 2007) and achieving goals (Labroo and Kim 2009). The majority of these studies focus on physiological correlates of effort, such as cardiovascular activity, as originally suggested by Wright (1996). Subjects in these studies are given a task that can vary in difficulty, such as a memory task (Richter et al. 2008). Effort is measured by the difference in the cardiovascular activity of subjects before and during performing a task. A common finding in this line of research is that subjects' effort initially increases with task difficulty but then drops. This effect appears to be quite universal in that it is observed regardless of the nature of a task (cognitive, physical, or social).

A natural question arises of whether the inverse- $U$ effect of difficulty on effort can be observed in an economic environment. Addressing this question is important for, at least, two reasons. First, understanding the role of difficulty and its interaction with other incentive elements, such as extrinsic monetary rewards, is relevant for principals who are seeking to design optimal incentive schemes for employees (Holmström 2017). Second, understanding the theoretical mechanisms behind the role of task difficulty in effort provision is relevant for researchers who are using models of effort provision to explain workers' behavior in the labor market or to predict the potential effects of policy interventions.

I seek to accomplish two goals: first, to empirically study the effect of difficulty on effort and its interaction with monetary rewards; and second, to use this evidence to improve our understanding of the mechanisms behind effort provision and, in particular, to clarify the modeling assumptions that are needed to generate different patterns of effort response to difficulty. ${ }^{6}$ In the empirical part, I set up an incentivized experiment that follows a chosen effort framework (Fehr et al. 1997; Abeler et al. 2010; Charness et al. 2012). Subjects assume the roles of agents who choose how much effort to exert in a series of projects. The probability of a project's success depends on a subject's chosen effort level and on a project's difficulty. Higher difficulty reduces the probability of success on a project for any given level of effort.

\footnotetext{
5 See Gendolla et al. (2012) for a comprehensive overview of the motivational intensity theory and behavioral evidence on its empirical validity.

6 The present study is not a test of motivational intensity theory. Rather, I use this theory as an inspiration to explore, both empirically and theoretically, the effect of task difficulty on effort in an economic environment and to compare this effect to the effect of monetary rewards.
} 
Monetary rewards consist of an unconditional (wage) and conditional (bonus) parts. The cost of effort is monetary and is subtracted from a project's monetary outcome. I vary difficulty, monetary rewards, and cost within subjects and observe how this exogenous variation affects subjects' effort levels. The chosen effort framework allows me to precisely define and observe difficulty and effort, and to derive sharp testable hypotheses.

To establish theoretical predictions, I use a very general model of effort choice under risk that allows for a utility function that is potentially non-separable in money and effort, as in Mirrlees (1971). Allowing for such a general utility function is necessary, since, as I show in the comparative statics analysis, the pattern of complementarity between effort and money in the utility function, together with the pattern of complementarity between effort and difficulty in the probability of success function, determines the overall effect of difficulty on effort. I consider two alternative models of agents' preferences. First, I use a benchmark Expected Utility (EU) model in which an agent chooses effort to maximize the weighted average of outcomes' utilities with the weights being the probabilities of each outcome. I show, in particular, that in the present experimental design a risk-averse agent would monotonically decrease her effort in response to higher difficulty. Interestingly, a model with an additively separable cost of effort, which is a workhorse model in the literature, predicts that higher difficulty would lead to no change in effort at all.

Given that the inverse-U relationship between effort and difficulty in the present experiment cannot be generated by the standard EU-approach, I consider an alternative model that can deliver such a relationship. The alternative model allows for probability weighting, as in the Cumulative Prospect Theory (CPT) (Tversky and Kahneman 1992). In this model, the agent also chooses effort to maximize a weighted average of outcomes' utilities, but now the weights are the probabilities that are transformed using a probability weighting function. I show that allowing for the probability weighting makes it possible to generate richer predictions about the potential effect of difficulty on effort. In particular, if the probability weighting function is inverse-S-shaped (respectively, S-shaped), the pattern of effort response to difficulty in the present experiment would be U-shaped (respectively, inverse-Ushaped). I argue that probability weighting is the only plausible channel that can generate a non-monotonic effect of difficulty on effort.

I find that monetary rewards affect effort in the predicted direction. Conditional rewards, on average, have a strong positive effect on effort, while the effect of unconditional rewards is positive but weak. These results are consistent with the previous findings in the literature (Gneezy and List 2006; DellaVigna and Pope 2018). Despite strong statistical significance, the economic significance of conditional rewards is somewhat disappointing: doubling the conditional rewards increases effort only by $20 \%$. Making the cost of effort steeper leads to a sharp decrease in effort, as predicted. This result is consistent with the findings in the contest literature (Dechenaux et al. 2015), as well as in the studies employing real-effort tasks (Goerg et al. 2019).

I find that the effect of difficulty on effort is inverse-U-shaped, which supports the hypothesis of an S-shaped probability weighting. This result is new to the economics 
literature. ${ }^{7}$ It does echo, however, the findings from the studies on the motivational intensity theory. Interestingly, the magnitude of the effect of difficulty is on par with the magnitudes of the effects of conditional rewards or costs. I find that difficulty mediates the effects of monetary rewards. Conditional rewards are most effective at the intermediate and high levels of difficulty. The inverse- $U$ effect of difficulty on effort refutes the benchmark EU-based model of effort and supports the alternative model with an S-shaped probability weighting. I further confirm this in a structural analysis by estimating the parameters of the probability weighting function. While a typical finding in the literature on risk preferences is an inverse-S-shaped probability weighting (Wu and Gonzalez 1996; Bruhin et al. 2010; l'Haridon and Vieider 2019), the subjects in the DellaVigna and Pope (2018) study also tended to underweight small probabilities (implied by an S-shaped weighting) in a real-effort experiment. ${ }^{8}$

The present findings have several important implications for the design of incentive schemes and modeling effort. The strong incentive effect of task difficulty suggests that managers should take this effect into account when assigning tasks to their subordinates. A manager can expect that it will take workers more effort to complete a moderately hard task than an easy task. However, workers might not devote as much effort to a very hard task as the manager would desire. This behavioral response to high difficulty can substantially lower a worker's performance by amplifying the direct negative effect of difficulty on performance. A manager, however, can counter this detrimental behavioral effect of difficulty using conditional rewards, since they are most effective when difficulty is high.

From a theoretical perspective, the workhorse model with an additively separable cost of effort might not be a good behavioral assumption in some cases. My results suggest that supplementing the workhorse model with probability weighting can better explain certain patterns of effort provision and yield higher predictive power. The implications of probability weighting on effort provision in other contexts, thus, deserve further investigation.

The uncovered effect of difficulty on effort has general methodological implications for using the existing effort tasks and designing new ones (Gill and Prowse 2012; Gächter et al. 2016). Experimental designs should control for task difficulty since it can have a strong and non-monotonic effect on subjects' effort. The interaction effect between task difficulty and incentives can be exploited to ensure that monetary incentive treatments do not suffer from a "ceiling-effect" problem. Setting task difficulty to an intermediate level should provide enough room for monetary incentives to affect subjects' effort.

I proceed as follows. Section 2 discusses the related literature. Section 3 describes the experimental procedures, design, and treatments. Section 4 presents

\footnotetext{
7 It should be noted that some studies in economics do discuss task difficulty and effort in other contexts. For example, Cassar and Meier (2018)[P. 225] propose a positive relationship between effort and difficulty when work is meaningful. In their example, higher difficulty is positively correlated with greater work meaning. Greater work meaning, in turn, will produce higher intrinsic motivation for the work and higher effort.

8 There are, however, exceptions from the inverse-S-shaped probability weighting in the literature on risk preferences, as well (Wilcox 2015b).
} 
the theoretical framework and derives testable hypothesis. Section 5 discusses the results of the experiment and estimates a structural model motivated by the observed behavioral patterns. Section 6 concludes.

\section{Related literature}

Most closely related to my design is the research by Vandegrift and Brown (2003) that studies the interactive effect of task difficulty and conditional monetary rewards on performance in a tournament environment. It finds that monetary rewards do not have any effect on performance for easy tasks, but do have a positive effect for difficult tasks. ${ }^{9}$ My results confirm the existence of the interaction effect between task difficulty and conditional rewards, while simultaneously extending them by presenting new evidence on the direct effect of task difficulty on effort. An additional contribution of my work is that it proposes and tests a novel theoretical mechanism behind the observed behavior.

Closely related to the effect of task difficulty on effort and its interaction with conditional rewards is the literature on goal-setting. Corgnet et al. (2015) conduct a laboratory principal-agent experiment and find that principals tend to set challenging but attainable performance goals for agents, which increases agents' performance relative to a no-goals baseline. They also report that the effect of goalsetting on effort is stronger under high monetary rewards. Smithers (2015) conducts a laboratory experiment and finds that setting exogenous goals in an addition task increases subjects' performance, with the effect being most pronounced in the male participants. Goerg and Kube (2012) conduct a field experiment at a campus library in which subjects were paid to sort books. They report that both exogenous and endogenous goal-setting leads to higher performance. These results are similar to the present findings, however, goal difficulty and task difficulty are not equivalent (Campbell and Ilgen 1976). Apart from having a difficulty component, goals also have a reference point component (Heath et al. 1999).

Going beyond the individual decision-making setting, the question of what drives effort levels takes a central place in the contest literature. This literature, however, does not explicitly consider the difficulty of winning a contest. One can interpret the number of players in a contest as a variable that is positively related to the difficulty of winning a prize. Such an interpretation is possible since increasing the number of players decreases the probability of winning a prize, all else equal, which is consistent with the definition of difficulty assumed in the present paper. While the theoretical relationship between the number of players and effort is ambiguous, experiments typically find a decreasing relationship (Dechenaux et al. 2015).

The analysis of the effects of conditional and unconditional rewards in the present work is related to the literature on the behavioral effects of monetary rewards. Hossain and List (2012) conduct a field experiment at a Chinese manufacturing firm. They

\footnotetext{
9 McDaniel and Rutström (2001) report that for a difficult task, increasing penalty for bad performance tends to induce more effort from subjects, though the study does not vary task difficulty.
} 
randomly assign workers to one of two conditions: in one condition, workers are paid a bonus upon reaching a given performance goal; and in the other condition, workers are paid a bonus in advance and lose it if they do not reach a performance goal. Consistent with the loss aversion hypothesis, the workers' performance was higher in the second condition. Gneezy and List (2006) conduct a field experiment at a campus library in which they vary the unconditional rewards paid to their subjects for arranging books. They find that increasing rewards has a positive but short-lived effect on the subjects' effort. A similar finding is reported by Jayaraman et al. (2016) who study the effort response of tea pluckers in India to an increase in their unconditional rewards caused by a change in contracts. Hennig-Schmidt et al. (2010) show that the positive effect of unconditional rewards occurs only when workers understand the benefit of their work to the principal, which triggers positive reciprocity. The weakly positive effect of unconditional rewards reported in the present paper is consistent with their findings.

Apart from the literature in economics, the present work is inspired by, and thus related to, the literature in psychology on motivational intensity theory (Brehm and Self 1989; Wright 1996). The present paper clarifies the link between task difficulty and effort from the perspective of economic theory and confirms the existence of an inverse-U relationship in an economic environment. Richter et al. (2008) use a laboratory experiment in which students participated in several rounds of a memory task (Sternberg 1966). The difficulty of the task was manipulated by the time during which the sequence of letters to be memorized appeared on the screen. Subjects' cardiovascular activity was evaluated right before and during the task, and the difference was used as a measure of effort. The study finds that effort increases up to the "high" level of difficulty and drops sharply at the "impossible" level. Smith et al. (1990) use a different task in which subjects had to give a convincing speech to an audience. The difficulty of the task depended on how convincing the speech should have been. The study measured effort using cardiovascular activity before and during the task. Effort due to anticipated difficulty (measured just before the performance) followed the same inverse-U pattern as effort during the performance. The inverse- $U$ pattern of effort due to anticipated difficulty is also reported by Wright et al. (1986). The subjects in the study did not actually perform a task, but rather were given task instructions (a variation on the memory task) along with an explicit statement about its difficulty after which the cardiovascular measurements were taken. The inverse- $U$ pattern of efforts in response to difficulty is found in the survey data, as well. Brockner et al. (1992) study how work effort is related to job insecurity (which can be interpreted as the difficulty of staying on a job) in the survey of workers in a nation-wide store chain and find that effort is highest at the intermediate level of job insecurity.

\section{Experimental design}

\subsection{Procedures}

The experiment was conducted at the ExCEN lab at Georgia State University (GSU) in May-June 2015. A total of 98 subjects participated in the experiment over the 
course of six sessions. The subjects were recruited using an automated system that randomly invited participants from a pool of more than 2000 students who signed up to participate in economic experiments. The subjects in the study were undergraduate students at GSU invited to participate via email. Each session was run on computers and lasted for roughly $1.5 \mathrm{~h}$. The subjects received a show-up fee of $\$ 5$ and the payoffs from decisions tasks. ${ }^{10}$ The average payment per subject was $\$ 45.89$ (the minimum payment was $\$ 5$, and the maximum was $\$ 100$ ), including the show-up fee.

Table 1 summarizes the demographic characteristics of the sample. The sample had equal shares of males and females. The racial composition was dominated by African American students: they accounted for $62 \%$ of the sample, while Caucasian students represented $14 \%$ of the sample. An average student's age was slightly above 21 years. The majority of subjects were in the advanced stages of a college program: more than half of participants were either juniors or seniors. Only $10 \%$ of the subjects came from an Economics or Finance major, which alleviates the concern that the observed behavior could be driven by the subjects sophisticated in economics.

\subsection{Effort task}

In each round of the effort task, a subject was given a project that had two possible outcomes: success or failure. ${ }^{11}$ A project was presented to subjects graphically, with outcomes and probabilities shown both in numerical format and as colored bars. The left part of the screen showed the monetary outcomes (revenue, cost, and profit) in the case of success, while the right part of the screen showed the monetary outcomes in the case of failure. The probabilities corresponding to each outcome were displayed below the monetary outcomes. At the bottom of the screen was a slider which subjects could use to input their effort level.

Each project was characterized by four treatment variables that varied across rounds for each subject. These variables are: bonus $(z)$, wage $(w)$, difficulty $(\theta)$, and cost $(k)$. In the case of success, a project yielded a high revenue (the sum of a wage and a bonus), and in the case of failure it yielded a low revenue (a wage only). Wage represents an unconditional (on performance) reward and bonus represents a conditional reward. The difficulty of a project affected the probability of success. Higher difficulty resulted in a lower probability of success for any given level of effort. The cost variable affected the steepness of the cost-of-effort function. The experiment was presented to subjects in a meaningful labor context with terms such as "revenue," "effort," and "difficulty.", 12 While it is possible that the meaningful context can have a framing effect, I believe that the benefits of using context in the present

\footnotetext{
$\overline{10}$ In each session subjects also participated in a supplementary incentivized risk elicitation task, which was a part of a different project.

11 Appendix A provides sample screenshots of the software, which was programmed in z-Tree (Fischbacher 2007).

12 The experimental instructions (provided in Appendix B), however, did note use terms "wage" and "bonus." Only terms "high" or "low revenue" were used, where a high revenue is a sum of a wage and a bonus, and a low revenue is a wage.
} 
experiment outweigh potential costs. First, context enhances subjects' understanding of an arguably complex decision-making task (Alekseev et al. 2017; Hsiao et al. 2019). And second, the labor context is appropriate given that the present study seeks to contribute to the understanding of effort provision.

Subjects could choose any integer effort level $a$ between 0 and 100 percent. The chosen level of effort had a twofold effect: on the probability of success, and on a project's profit (revenue minus cost). Higher effort increased the probability of success but led to lower profits. The subjects incurred the cost of effort regardless of the outcome of a project. When deciding what effort level to choose, the subjects therefore faced a trade-off between a higher chance of the project being successful and lower profits. By moving the effort slider, subjects could clearly observe how a given effort level translates into monetary outcomes and probabilities for each outcome.

The use of the chosen, rather than real, effort framework is common in tournament (Bull et al. 1987) and principal-agent experiments (Fehr et al. 1997; Abeler et al. 2010; Charness et al. 2012). The primary motivation for this design is to allow for a clean test of theoretical predictions. Brüggen and Strobel (2007) demonstrate that the chosen effort framework yields qualitatively similar results to the real effort framework in their setting, while allowing for a greater control.

The probability of success $p$ as a function of effort $a$ and difficulty $\theta$ was computed as

$$
p(a, \theta)=a / 2+(1-\theta) / 2,
$$

so that, effectively, the probability of success was a simple average between an effort level and a project's ease, $1-\theta .{ }^{13}$ The cost of effort was computed as the square of effort multiplied by the cost variable $k$ :

$$
c(a)=k a^{2}
$$

to induce a convex cost schedule. The subjects were informed of the linear relationship between the probability of success and effort and of the convex relationship between the costs and effort.

Subjects received feedback on the outcome of a project in every round. ${ }^{14}$ The feedback was provided to ensure that subjects had a good understanding of the task, since quick feedback is crucial for learning and improving performance (Balzer et al. 1989; Hoch and Loewenstein 1989). This was justified by the complexity of the decision task, which had many alternatives to choose from (specifically, 101 levels of effort) and several decision-relevant variables to consider. After the outcome of a project was determined, the subjects could review the results of the current round on a summary screen.

\footnotetext{
13 The linear specification with equal weights for effort and difficulty was chosen to simplify the analysis and because it was easy to convey to subjects.

14 All random outcomes were realized by a computer. While using a computer may raise credibility concerns among some subjects, this design was implemented due to its procedural convenience.
} 
Table 1 Socio-demographic characteristics of the sample

\begin{tabular}{ll}
\hline Characteristic & Mean \\
\hline Gender & \\
Male & 0.48 \\
Female & 0.48 \\
Other/prefer not to answer & 0.04 \\
Race and age & \\
Black or African American & 0.62 \\
Asian & 0.18 \\
White or Caucasian & 0.14 \\
Other/prefer not to answer & 0.05 \\
Age & 21.29 \\
Year in program and major & \\
Freshman & 0.04 \\
Sophomore & 0.18 \\
Junior & 0.24 \\
Senior & 0.45 \\
Graduate & 0.05 \\
Prefer not to answer & 0.03 \\
Econ or finance major & 0.10 \\
\hline
\end{tabular}

Each subject played between 15 and 19 rounds of the effort task, which were preceded by five practice rounds. ${ }^{15}$ After completing all the rounds, the payoff for the effort task was determined by randomly selecting one round. While paying randomly for one round is theoretically not incentive compatible with non-EU models (Harrison and Swarthout 2014; Cox et al. 2015), the provision of feedback after each round (i.e., playing out choices sequentially but paying for one choice randomly in the end) might alleviate this concern in practice (though not in theory), as suggested by Cox et al. (2015). They show that estimated risk preferences are not significantly different between a treatment in which subjects made, and were paid for, only one choice (theoretically incentive compatible with any model) and a treatment in which subjects made multiple choices with feedback and were paid for a random round.

The four project characteristics (difficulty, wage, bonus, and cost) changed randomly across rounds, and subjects were aware of this. Each distinct combination of the values of these treatment variables represents a treatment. The three monetary treatment variables $(w, z$, and $k$ ) assumed one of the two possible values. Wage $w$ assumed the values of 1 or 2 , bonus $z$ assumed the values of 2 or 4 , and cost $k$ assumed the values of 1 or 2 . These values were multiplied by $\$ 10$ and then presented to subjects. For instance, a treatment with $w=1$ and $z=2$ corresponded to a

\footnotetext{
15 The practice rounds gave subjects the opportunity to familiarize themselves with the interface and prepared them for decision-making in the paying rounds. Given that subjects likely used the practice to play with the software and did not consider their choices carefully, the data from the practice rounds is not used in the analysis.
} 
project with a low revenue of $\$ 10$ and a high revenue of $\$ 30=\$ 10+\$ 20$. Similarly, given an effort level of $40 \%$ and a treatment with $k=2$, the cost of effort would be $\$ 3.2=\$ 20 \times 0.4^{2}$. Difficulty assumed five values: $0,0.25,0.5,0.75$, and 1 , which was important for identifying a potentially non-monotonic effect on effort. ${ }^{16}$ The treatments were constructed from the permutations of the values of the treatment variables. The order of treatments was randomized on the subject level. Each subject made an effort choice in a given treatment only once. ${ }^{17}$ Appendix A provides the summary of the treatments used in the experiment.

The within-subject design was chosen for three main reasons. First, the large number of treatments made it impractical to use a between-subject design. Second, the within-subject design allows for a deeper analysis of the subjects' data and improves statistical power. Third, even though it is possible that subjects experience the experimenter demand effect by observing all the treatments (Charness et al. 2012), it was unlikely in the present experiment. A relatively large number of treatment variables changing randomly between the rounds would make it extremely hard for subjects to infer patterns and the expected responses.

\section{Theoretical framework}

\subsection{Environment}

Consider an agent who works on a project with a stochastic binary outcome, success or failure. The project yields a wage $w \geqslant 0$ regardless of the outcome and a bonus $z \geqslant 0$ in the case of success. This is a standard setting in the principal-agent literature (Laffont and Martimort 2009) The novel assumption is that the probability of success in the project is determined, in addition to the agent's effort $a \in[0,1]$, by the project's difficulty $\theta \in[0,1]$. The vector of the values of the project's characteristics is denoted as $\pi \equiv(w, z, \theta)$.

Let $X$ be a Bernoulli random variable encoding the project's outcome. The agent's revenue from the project is $Y=w+z X$. The probability of success $p:[0,1] \times[0,1] \mapsto[0,1]$ is a function of effort $a$ and difficulty $\theta$. I assume that $p$ is twice continuously differentiable, increasing and concave in effort, and decreasing in difficulty.

If the cdf of $X$ conditional on effort and difficulty is $F(x \mid a, \theta)$ and pmf is $f(x \mid a, \theta)=x p(a, \theta)+(1-x)(1-p(a, \theta))$ (for $x \in\{0,1\}$, and 0 otherwise), then for $0 \leqslant x<1$ we have $F_{a}(x \mid a, \theta)=-p_{a}(a, \theta)<0$. This implies that the agent has an incentive to exert more effort, since the project endowed with a high effort level

\footnotetext{
${ }^{16}$ Most of the analysis is focused on the three levels of difficulty: $0,0.5$, and 1 , which are enough to detect a non-monotonic effect. The other two values of difficulty were included for exploratory purposes and are mostly omitted from the discussion for greater clarity.

17 An alternative arrangement would have been to make subjects repeat their choices for each treatment. Repeated choices would have helped to reduce the noise associated with a single choice. However, making subjects repeat their choices even one time would have sufficiently increased the length of an already lengthy experiment, which was undesirable.
} 
first-order stochastically dominates the project with a low effort level. However, there is a trade-off in that more effort leads to higher disutility from exerting it.

\subsection{Preferences}

I assume that the agent has preferences over money $y$ and effort $a$ represented by a utility function $u: \mathbb{R}_{+} \times[0,1] \mapsto \mathbb{R}$. The $u$ function is assumed to have the standard properties: it is twice continuously differentiable, strictly increasing and concave in money, and is strictly decreasing and concave in effort, i.e., the marginal disutility of effort increases. I use a very general utility function that is potentially non-separable in money and effort, as in Mirrlees (1971), as opposed to a more commonly used additively separable function (Abeler et al. 2011; Hossain and List 2012; Jayaraman et al. 2016; DellaVigna and Pope 2018). The reason for this choice is that the additively separable specification turns out to be very restrictive in terms of the comparative statics effect of difficulty on effort.

Given that the agent exerts effort in a risky environment, I consider two alternative models of the agent's preferences and show that the assumptions about these preferences play a crucial role in determining the effect of difficulty on effort. The first natural assumption is the EU model.

Assumption 1.A (EU) The agent's risk preferences are characterized as

$$
U(a \mid \pi) \equiv \mathbb{E} u(Y, a)=\sum_{x=0}^{1} u(w+z x, a) f(x \mid a, \theta) .
$$

I also explore an alternative model that allows for non-linear probability weighting, as in the CPT (Tversky and Kahneman 1992) or the Rank-Dependent Utility model (Quiggin 1982). Probability weighting turns out to be critical for producing the nonmonotonic effect of difficulty on effort.

Assumption 1.B $(P W)$ The agent's risk preferences are characterized as

$$
\tilde{U}(a \mid \pi) \equiv \tilde{\mathbb{E}} u(Y, a)=\sum_{x=0}^{1} u(w+z x, a) \tilde{f}(x \mid a, \theta),
$$

where $\tilde{f}(x \mid a, \theta)=x \tilde{p}(a, \theta)+(1-x)(1-\tilde{p}(a, \theta))$ is the decision weight of an outcome $x$, and $\tilde{p}(a, \theta)=\omega(p(a, \theta))$ is the success probability weighted by the probability weighting function $\omega:[0,1] \mapsto[0,1]$, twice continuously differentiable and strictly increasing with $\omega(0)=0$ and $\omega(1)=1$. 


\subsection{Optimal effort}

Under Assumption 1.A the agent chooses the optimal effort level $a^{*}$ given the parameters of the problem $\pi$ by maximizing $U(a \mid \pi)$. If $a^{*}=\arg \max U(a \mid \pi)$, then the first-order necessary condition must hold: ${ }^{18}$

$$
\mathbb{E}\left[u\left(Y, a^{*}\right) \frac{f_{a}\left(X \mid a^{*}, \theta\right)}{f\left(X \mid a^{*}, \theta\right)}\right]=-\mathbb{E} u_{a}\left(Y, a^{*}\right) .
$$

Equation (3) means that in the optimum the marginal benefit from exerting more effort on the left-hand side must be balanced by the marginal cost of effort on the right-hand side. The marginal benefit represents the expectation of the utility weighted by $f_{a} / f$, since the gain comes from the increased probability of success. It can be rewritten as $p_{a} \Delta u$, where $\Delta u \equiv u(w+z, a)-u(w, a)$ is the utility gain between the success and failure given effort $a$. Written in this form, the marginal benefit is the marginal increase in the probability of success multiplied by the utility gain. The marginal cost is the expected marginal disutility of effort. It can be rewritten using the Mean Value Theorem as $u_{a}+p z u_{y a}$, where the cross-partial is evaluated at some point $\left(\bar{y}, a^{*}\right), \bar{y} \in[w, w+z]$. This form will be useful for understanding the comparative statics of the model. ${ }^{19}$ All the above results also hold under Assumption 1 .B after replacing $U, \mathbb{E}, f$ and $p$ with $\tilde{U}, \tilde{\mathbb{E}}, \tilde{f}$ and $\tilde{p}$, respectively.

\subsection{Special cases}

Several special cases of the utility function $u$ permit closed-form solutions. The first case is a separable utility function, $u(y, a)=v(y)-c(a)$, which is a popular specification in the literature. In this specification the utility of money $v$ is linearly separable from the cost of effort $c$. Assume that $v: \mathbb{R}_{+} \mapsto \mathbb{R}$ is twice continuously differentiable, increasing and concave. With a quadratic cost of effort as in (2) and a linear probability of success as in (1), the optimal effort is

$$
a^{*}=\frac{v(w+z)-v(w)}{4 k} .
$$

A notable feature of this specification is that the optimal effort does not depend on the project's difficulty. As will be shown shortly, this is the consequence of the linearity of $p$ and the additive separability of $u$, under which the cross-partial derivatives

\footnotetext{
18 See Appendix F for all the derivations and proofs.

19 Given the generality of the assumed utility function, the first-order condition is not sufficient since the problem is not guaranteed to be globally concave. When $U$ is not globally concave, it is possible to get a local maximum, in which case one also needs to check the function values at the boundaries of the choice set to find the global maximum. The global maximum will always exist by the Extreme Value Theorem. Simulations show that for some parameter values, it is possible to run into corner solutions, which however does not invalidate the comparative statics results. They will still hold as weak inequalities. In what follows, I assume that $a^{*}$ is the interior global maximum of the agent's problem.
} 
of both functions are zero. The optimal effort increases with the bonus and decreases with the cost $k$, which is intuitive. The increase in the wage causes the optimal effort to go down if $v$ is strictly concave. This makes sense since if the agent can guarantee herself good result regardless of the outcome she will not have a strong incentive to exert effort. However, if $v$ is linear, the optimal effort does not depend on wage and assumes a particularly simple form: $z /(4 k)$.

The second case is a non-additively separable specification in which effort has a monetary cost to the agent, just like in the current experimental design, and the utility of money is exponential, $u(y, a)=v(y-c(a))=-e^{-\gamma(y-c(a))}$, with $\gamma>0$ being the constant absolute risk aversion (CARA) parameter. The benefit of using the exponential (CARA) utility is its analytical tractability. Assume that the cost of effort is quadratic and the probability of success is linear. It can be shown that in this case the optimal effort is given by

$$
a^{*}=\frac{A+\theta-\sqrt{(A+\theta)^{2}-2 /(k \gamma)}}{2}, \text { where } A \equiv \frac{1+e^{-\gamma z}}{1-e^{-\gamma z}},
$$

and the effect of difficulty on the optimal effort is negative because of the positive risk aversion parameter. Unlike in the additively separable case, $u$ has a positive cross-partial derivative, which drives this result. It is worth noting that the optimal effort will not depend on the wage. As in the previous case, the optimal effort will increase with the bonus and decrease with the cost.

\subsection{Comparative statics, difficulty}

Under Assumption 1.A, the effect of the project's difficulty on the optimal effort is given by

$$
\frac{d a^{*}(\pi)}{d \theta}=-\frac{z\left[p_{\theta}\left(a^{*}, \theta\right) u_{y a}\left(\bar{y}, a^{*}\right)+u_{y}\left(\overline{\bar{y}}, a^{*}\right) p_{a \theta}\left(a^{*}, \theta\right)\right]}{U^{\prime \prime}\left(a^{*} \mid \pi\right)},
$$

where $\bar{y}, \overline{\bar{y}}$ are some numbers on $[w, w+z]$. The sign of the effect crucially depends on the signs of the cross-partial derivatives of both $u$ and $p$. This effect can be concisely stated as follows.

Proposition 1.A If $\operatorname{sgn}\left(u_{y a}\right) \operatorname{sgn}\left(p_{a \theta}\right)<1$, then $\operatorname{sgn}\left(\frac{d a^{*}(\pi)}{d \theta}\right)=\operatorname{sgn}\left(p_{a \theta}-u_{y a}\right)$.

Assuming that $p_{a \theta} \neq 0$, the effect of difficulty will have the same sign as this cross-partial derivative. Intuitively, this implies that if effort and difficulty are complements in the probability function, it is optimal to increase effort in response to a higher difficulty. Since higher difficulty reduces the probability of success, the optimal response is to compensate this reduction. On the other hand, if effort and difficulty are substitutes in $p$, it is optimal to reduce effort, which makes the reduction in the probability of success even higher.

Using Assumption 1.B instead, the formula in (5) remains valid after the appropriate change of non-tilde characters to tilde characters. Expanding, one obtains 


$$
\frac{d a^{*}(\pi)}{d \theta}=-\frac{z\left[\omega^{\prime} p_{\theta}\left(a^{*}, \theta\right) u_{y a}\left(\bar{y}, a^{*}\right)+u_{y}\left(\overline{\bar{y}}, a^{*}\right)\left(p_{a \theta}\left(a^{*}, \theta\right) \omega^{\prime}+p_{\theta}\left(a^{*}, \theta\right) p_{a}\left(a^{*}, \theta\right) \omega^{\prime \prime}\right)\right]}{\tilde{U}^{\prime \prime}\left(a^{*} \mid \pi\right)},
$$

where $\omega, \omega^{\prime}$ and $\omega^{\prime \prime}$ are evaluated at $p\left(a^{*}, \theta\right)$. Note that if $\omega^{\prime \prime}=0$ we are back to the EU case, since there would be no probability weighting. The sign of the effect of difficulty on effort now depends, in addition to the signs of the cross-partial derivatives of $u$ and $p$, on the sign of $\omega^{\prime \prime}$. Assuming that $\omega^{\prime \prime} \neq 0$, the effect of difficulty in this case can be concisely stated as follows.

Proposition 1.B If $\operatorname{sgn}\left(u_{y a}\right) \operatorname{sgn}\left(p_{a \theta}\right)<1$ and $\operatorname{sgn}\left(u_{y a}\right) \operatorname{sgn}\left(\omega^{\prime \prime}\right)>-1$, then $\operatorname{sgn}\left(d a^{*}(\pi) / d \theta\right)=-\operatorname{sgn}\left(\omega^{\prime \prime}\right)$.

This result has an intuitive interpretation. If the agent exhibits probability pessimism, $\omega^{\prime \prime}>0$, she will reduce effort in response to a higher difficulty, as if she does not believe in her ability to affect the chances of success strong enough to accept the challenge. On the other hand, if the agent exhibits probability optimism, $\omega^{\prime \prime}<0$, she will raise effort in response to a higher difficulty.

The results obtained so far predict only a monotonic effect of difficulty on effort. The findings in psychology (Gendolla et al. 2012, 2008), however, suggest the existence of a non-monotonic inverse-U pattern. The question is what features of the model can produce such a non-monotonic effect. An inspection of the comparative statics formulas (5) and (6) reveals that in order to achieve a non-monotonic effect, the terms containing $\theta$ need to change their sign as $\theta$ changes. The only term that naturally has this feature is $\omega^{\prime \prime}$ since experiments often find an inverse-S shape of the probability weighting function (Wu and Gonzalez 1996; Bruhin et al. 2010), which is concave for low values of $p$ and convex for high values of $p$.

Assume for simplicity that both cross-partial derivatives or $u$ and $p$ are zero and that $\omega$ is inverse-S-shaped. The sign of the effect of difficulty then would change from positive, for small $p$, to negative, for high $p$. The difficulty is inversely related to $p$, hence one could expect that effort would increase (decrease) for high (low) values of difficulty, which implies a U-shaped pattern. Figure $1 \mathrm{~b}$ illustrates this point by plotting the optimal effort as a function of difficulty for three different shapes of $\omega$. In the simulation, I use the monetary cost of effort specification with the CRRA utility of money $u(x)=x^{1-\gamma} /(1-\gamma)$ with $\gamma=0.2$ and the one-parameter Prelec (1998) weighting function $\omega(p)=\exp \left(-(-\ln (p))^{\alpha}\right)$. The cost and probability of success functions are specified as before. The optimal effort as a function of difficulty is U-shaped for an inverse-S-shaped probability weighting function and is inverse-Ushaped for an S-shaped probability weighting function. When there is no weighting, the optimal effort monotonically declines in difficulty as predicted by Proposition 1.A, since $u_{y a}>0$ in this specification.

\subsection{Comparative statics, bonus and wage}

The effect of bonus on optimal effort is given by 


$$
\frac{d a^{*}(\pi)}{d z}=-\frac{p\left(a^{*}, \theta\right) u_{y a}\left(w+z, a^{*}\right)+p_{a}\left(a^{*}, \theta\right) u_{y}\left(w+z, a^{*}\right)}{U^{\prime \prime}\left(a^{*} \mid \pi\right)}
$$

which leads to the following result:

Proposition 2 If $u_{y a} \geqslant 0$, optimal effort will increase with bonus.

This prediction makes sense intuitively, as a higher bonus means a better outcome in case of success, which in turn justifies higher effort. Both additively separable and exponential utility cases are examples of this result. Proposition 2 clarifies, however, that this result holds unambiguously only when money and effort are complements in the utility function.

The effect of wage on optimal effort is given by

$$
\frac{d a^{*}(\pi)}{d w}=-\frac{\mathbb{E} u_{y a}\left(Y, a^{*}\right)+z p_{a}\left(a^{*}, \theta\right) u_{y y}\left(\bar{y}, a^{*}\right)}{U^{\prime \prime}\left(a^{*} \mid \pi\right)},
$$

which leads to the following result:

Proposition 3 If $u_{y a} \leqslant 0$, optimal effort will decrease with wage.

This means that if the agent can guarantee herself higher revenue regardless of the outcome, she has an incentive to exert low effort, provided that $u$ is submodular. This is true, for example, in the additively separable case.

Propositions 2 and 3 will still hold under the probability weighting assumption, since $\tilde{p}$ and $\tilde{p}_{a}=\omega^{\prime} p_{a}$ have the same signs as $p$ and $p_{a}$, respectively.

\subsection{Testable hypotheses}

In the experiment, the probability of success function in (1) is linear and therefore $p_{a \theta}=0$. Moreover, the use of the chosen effort framework allows me to determine the sign of the cross-partial $u_{y a}$ unambiguously. Since effort has a monetary cost to the agent, the utility function becomes $u(y, a)=v(y-c(a))$, where $v: \mathbb{R}_{+} \mapsto \mathbb{R}$ is the utility of money, assumed to be twice continuously differentiable, increasing and concave, and $c:[0,1] \mapsto \mathbb{R}_{+}$is the cost of effort function given by (2), twice continuously differentiable, increasing and convex. Then the cross-partial of the utility function is $u_{y a}=-c^{\prime} v^{\prime \prime} \geqslant 0$, which implies that $\operatorname{sgn}\left(d a^{*} / d \theta\right)=-\operatorname{sgn}\left(u_{y a}\right) \leqslant 0$.

The analysis of the comparative statics shows that the effect of difficulty cannot be signed unambiguously, as different preference assumptions (EU, inverse-Sshaped probability weighting, or S-shaped probability weighting) yield competing predictions. The use of the chosen effort framework does allow me to sign the predicted effect of difficulty within a given preference assumption, hence the data will 


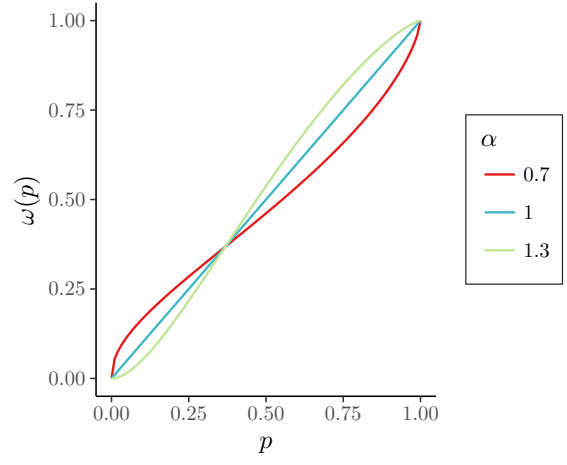

(a) Probability Weighting Function

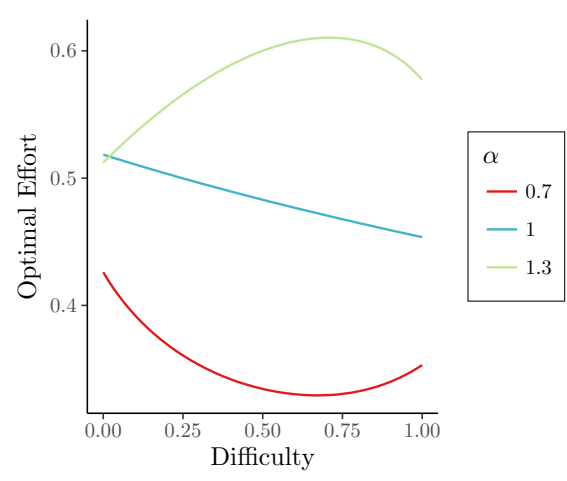

(b) Effect of Difficulty on Effort

Fig. 1 Comparative statics under probability weighting

ultimately determine the winning assumption. Below I summarize the competing hypothesis derived so far. ${ }^{20}$

Hypothesis 1.A (Difficulty, decreasing) Subjects' average effort will monotonically decrease with the project's difficulty.

Hypothesis 1.B (Difficulty, U-shape) Subjects' average effort will first decrease, reach a minimum, and then increase with the project's difficulty.

Hypothesis 1.C (Difficulty, inverse-U-shape) Subjects' average effort will first increase, reach a maximum, and then decrease with the project's difficulty.

Turning to the effect of incentives, in the experiment $u$ is supermodular and Proposition 2 applies directly leading to the following hypothesis:

Hypothesis 2 (Bonus) Subjects' average effort will increase with the project's bonus.

In the experiment, $u_{y a} \geqslant 0$ and therefore Proposition 3 cannot be applied to sign the effect of wage. We have seen that in the special case of exponential utility the optimal effort level did not depend on the wage. In the numerical simulations with CRRA utility, effort monotonically increases with wage. It is, therefore, reasonable to expect the following behavior.

\footnotetext{
20 The comparative statics predictions are derived under the assumption of deterministic choice. Appendix D.3 shows that the model's predictions also hold under the assumption of stochastic choice. In the case of stochastic choice the predictions are in terms of expected, or average, effort, which is reflected in the hypotheses stated below.
} 
Hypothesis 3 (Wage) Subjects' average effort will monotonically increase with the project's wage.

The experimental design includes one more treatment variable, $k$, which is the scaling factor of the cost of effort function. The comparative statics for the cost variable cannot be derived in a general model, since $k$ only arises in the parametrizations of the model. The effect of $k$ on the optimal effort, however, can be evaluated in the special cases we considered earlier. These special cases suggest the following behavior.

Hypothesis 4 (Cost of effort) Subjects' average effort will decrease with the cost of effort.

\section{Results}

I begin by presenting the treatment effects of the monetary treatment variables and difficulty. ${ }^{21}$ Then I show how the treatment effects of the monetary variables change conditional on the value of difficulty. The analysis concludes with the structural estimation of the model.

\subsection{Treatment effects}

Table 2 shows the summary of the treatment effects. Figure 2 shows the empirical CDFs of subjects' effort levels for different values of the treatment variables. ${ }^{22}$ Since the dataset has a panel structure (every subject experiences multiple treatments), I first compute the mean effort levels for each value of a treatment variable for each subject and then report statistics for these subject-level means. To analyze the effect of wage, I use the subset of observations with $k=1$. For the full sample, wage and cost are highly correlated, which is due to the nature of the design. In the experiment, cost cannot exceed wage, otherwise a negative profit could occur and subjects could lose money. When analyzing the effect of cost, the sample is restricted to observations in which $w=2$ for the same reason.

Figure 3 summarizes the treatment effects results by plotting the average treatment effects (ATEs) for all the treatment variables. An ATE for a variable is calculated as the change in the mean effort level (shown in Table 2) when the variable increases. The effect of difficulty is broken down into the first increase from 0 to 0.5 (Difficulty 1 ) and the second increase from 0.5 to 1 (Difficulty 2). The treatment variables are sorted by the magnitude of the ATE, which makes it easy to compare the effectiveness of different variables in affecting effort.

\footnotetext{
21 Appendix D.4 presents the analysis of the individual heterogeneity in treatment effects.

22 Figures D.1 and D.2 in Appendix D.1 additionally show the means and histograms of effort.
} 
The inverse-U effect of difficulty picks Hypothesis 1.C as the winning hypothesis and is new to the economics literature. The intuition behind this result is the following. When the probability weighting function is S-shaped, high difficulty corresponds to the case of low probability of success where the probability weighting function is convex (probability pessimism) and hence higher difficulty leads to lower effort. On the other hand, low difficulty corresponds to the case of high probability of success where the probability weighting function is concave (probability optimism) and hence higher difficulty leads to higher effort. This result, however, is consistent with the previous findings in psychology on the motivational intensity theory, as reviewed by Gendolla et al. (2012). This literature finds that subjects increase their effort in response to higher difficulty up to a certain point after which effort is decreased. A remarkable feature of the present result is that changing difficulty produces a powerful incentive effect that is comparable to the effect of doubling the conditional reward or doubling the cost of effort, see Fig. 3. The effect of difficulty on effort, however, is more noisy than the effects of monetary rewards or cost.

Result 1 Subjects' average effort first increases, reaches a maximum, and then decreases with the project's difficulty.

The effects of conditional and unconditional rewards are consistent with the previous findings in the literature. The positive effect of a higher bonus supports Hypothesis 2 and is in line with the results reported in Lazear (2000) and Hossain and List (2012) and more recently by DellaVigna and Pope (2018) and de Quidt et al. (2018). Some papers suggest that when conditional rewards are too small or too high, they can backfire and lead to lower effort either through crowding out of intrinsic motivation or choking-under-pressure (Gneezy et al. 2011). I do not observe these negative effects in my data because the chosen effort framework leaves little space for these two channels and also because the level of conditional rewards in the experiment apparently did not hit either extreme. I do note, however, that while the effect of bonus is highly statistically significant, its economic significance is somewhat disappointing. Recall that in the experiment the monetary value of a bonus doubles from $\$ 20$ to $\$ 40$. This substantial change in stakes, however, does not lead to doubling effort, as a simple risk-neutral model (4) would suggest. Effort increases only by $20 \%$ or by 0.52 standard deviations.

Result 2 Subjects' average effort increases with the project's bonus.

The weakly positive effect of higher wage supports Hypothesis 3 and is also consistent with the previous studies on the effect of unconditional rewards. A common finding is that unconditional rewards are effective in the short-run (Gneezy and List 2006; Jayaraman et al. 2016) and when the reciprocity channel exists (Cohn et al. 2014; Hennig-Schmidt et al. 2010). Since the subjects in the experiment were unlikely to have reciprocal motives - their performance did not benefit anyone else but them-the increase in wage did not result in a significant increase in effort. 
Table 2 Summary of treatment effects

\begin{tabular}{llll}
\hline Variable & Predicted effect & Mean effort Levels & $p$-value \\
\hline Difficulty 1 & Ambiguous & $\bar{a}(\theta=0)=0.57, \bar{a}(\theta=0.5)=0.65$ & 0.001 \\
Difficulty 2 & Ambiguous & $\bar{a}(\theta=0.5)=0.65, \bar{a}(\theta=1)=0.54$ & 0.002 \\
Bonus & Positive & $\bar{a}(z=2)=0.53, \bar{a}(z=4)=0.64$ & $<0.001$ \\
Wage & Positive & $\bar{a}(w=1)=0.58, \bar{a}(w=2)=0.61$ & 0.04 \\
Cost & Negative & $\bar{a}(k=1)=0.61, \bar{a}(k=2)=0.49$ & $<0.001$ \\
\hline
\end{tabular}

Difficulty 1 refers to the change in difficulty from 0 to 0.5 . Difficulty 2 refers to the change in difficulty from 0.5 to 1 . The $p$-values are from a Wilcoxon signed rank test (two-sided)

(a) Difficulty

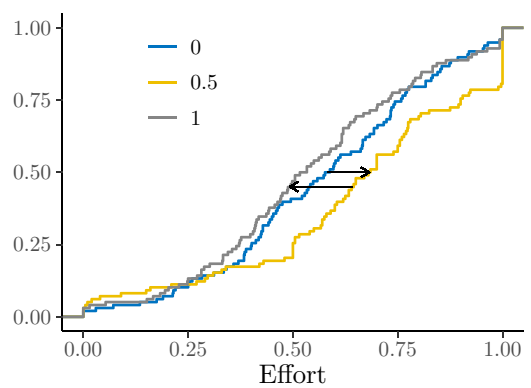

(c) Wage

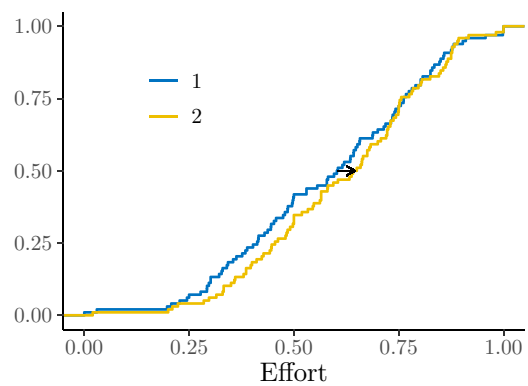

(b) Bonus

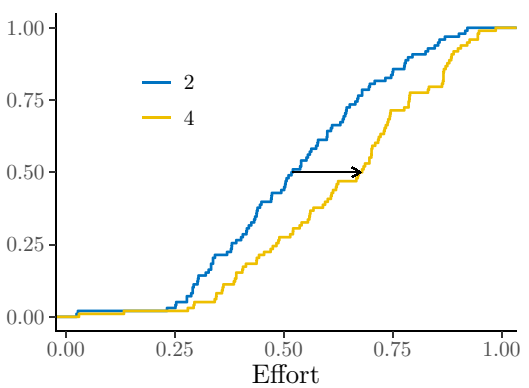

(d) Cost

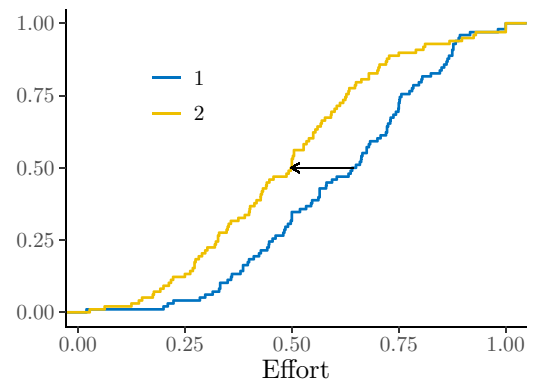

Note: The graph shows empirical CDFs of effort levels broken down by a treatment variable and the value of a variable. Effort levels used to plot CDFs are subject-level mean effort levels for each value of a treatment variable.

Fig. 2 Empirical CDFs of effort by treatment variable

Result 3 Subjects' average effort weakly increases with the project's wage.

The strong negative effect of higher cost supports Hypothesis 4. While the effect of cost of effort is relatively unexplored in the studies of individual effort, the contest literature, as reviewed by Dechenaux et al. (2015), finds that higher costs generate lower 


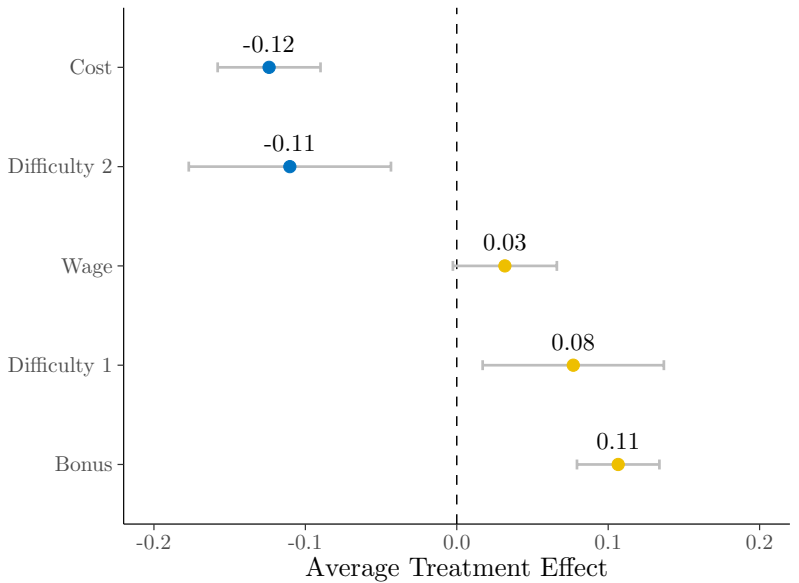

Note: The graph plots the ATEs of increasing the value of each treatment variable, ordered by the magnitude of the effect. The change in difficulty is broken down into the first increase from 0 to 0.5 (Difficulty 1) and a second increase from 0.5 to 1 (Difficulty 2). Horizontal bars represent $95 \%$ confidence intervals from a paired $t$-test.

Fig. 3 Comparison of ATEs

effort. The results in the present individual-effort experiment are therefore consistent with the results in contests. The present results are also consistent with a recent realeffort study by Goerg et al. (2019) that employs an individual-choice setting.

Result 4 Subjects' average effort decreases with the cost of effort.

\subsubsection{Robustness}

The panel design of the experiment allows for a robustness check based on using ceteris paribus pairs. A pair of samples of effort is called a ceteris paribus pair $(C P$ pair) for a treatment variable $x$, if only $x$ changes within a pair while the rest of the treatment variables are constant. Since hypotheses are derived from comparative statics results, the ceteris paribus test is a more direct test of hypotheses. Table E.3 in Appendix E confirms that treatment effects hold under a ceteris paribus test: the direction of the treatment effects, with a few exceptions, is consistent across all the $C P$-pairs. Table 3 presents the estimates of a panel regression with subject fixed effects, which includes a squared term for difficulty to capture the non-monotonic effect. The negative and statistically significant coefficient on the squared term for difficulty confirms the existence of an inverse- $U$ relationship between difficulty and effort. 


\subsection{Interaction effects}

Is it possible that difficulty mediates the effects of monetary rewards and cost? To explore this possibility, I compute the ATEs of bonus, wage, and cost at different values of difficulty and plot them on Fig. 4. The figure shows that higher difficulty in general increases the treatment effects of the monetary variables but in many cases this interaction is too small to be statistically significant. In particular, increasing difficulty from 0 to 1 increases the ATE (reduces the negative ATE) of cost by $0.03(p$-value $=0.409, t$-test $)$, increases the ATE of wage by $0.04(p$-value $=0.225$, $t$-test), and increases the ATE of bonus by 0.08 ( $p$-value $=0.004, t$-test $){ }^{23}$ Hence the data suggest that conditional rewards are most effective in stimulating effort when difficulty is high. This result is consistent with Vandegrift and Brown (2003) who also find that conditional rewards are more effective on difficult tasks.

\subsection{Structural analysis}

In this section I ask whether a simple structural model can explain the observed behavioral patterns. As highlighted by the theoretical analysis in Sect. 4, the inverse$\mathrm{U}$ pattern of effort response to difficulty can be accommodated by the model with probability weighting, but not by the EU model.

\subsubsection{Estimation procedures}

Consider an agent with preferences $\beta$ who faces treatment $\delta$. The utility of effort choice $a \in A=\{0,0.01, \ldots, 1\}$ will be given by

$$
U(a \mid \delta, \beta)=\omega\left(p(a, \theta) \mid \beta_{\omega}\right) u\left(w+z, a \mid \beta_{u}\right)+\left(1-\omega\left(p(a, \theta) \mid \beta_{\omega}\right) u\left(w, a \mid \beta_{u}\right),\right.
$$

where $\beta=\left(\beta_{\omega}, \beta_{u}\right), \omega:[0,1] \mapsto[0,1]$ is the probability weighting function parametrized by $\beta_{\omega}$, and $u: \mathbb{R}_{+} \times[0,1] \mapsto \mathbb{R}$ is the utility function parametrized by $\beta_{u}$. In the experiment, the utility function $u$ is $u\left(y, a \mid \beta_{u}\right)=v\left(y-c(a) \mid \beta_{u}\right)$. The cost function $c$ and the probability of success function $p$ are defined by equations (2) and (1), respectively.

I assume that $\omega$ takes the two-parameter Prelec form (Prelec 1998), which is frequently used in applied work (Wilcox 2015a; l'Haridon and Vieider 2019) and has been shown to have good empirical properties (Stott 2006), with $\beta_{\omega}=(\alpha, \psi)$. Parameter $\alpha$ determines the shape of the function, while parameter $\psi$ determines the scale of the function.

$$
\omega\left(p \mid \beta_{\omega}\right)=\exp \left(-\psi(-\ln p)^{\alpha}\right)
$$

\footnotetext{
${ }^{23}$ See Table D.1 in Appendix D.2 that reports the panel regression results with subject fixed effects and interaction terms.
} 
Table 3 Panel regression results

\begin{tabular}{lllll}
\hline Variable & Coefficient & SE & Statistic & $p$-value \\
\hline Bonus & 0.066 & 0.007 & 9.581 & $<0.001$ \\
Wage & 0.015 & 0.017 & 0.873 & 0.383 \\
Cost & -0.108 & 0.016 & -6.824 & $<0.001$ \\
Difficulty & 0.37 & 0.084 & 4.4 & $<0.001$ \\
Difficulty $^{2}$ & -0.408 & 0.082 & -5.004 & $<0.001$ \\
\hline
\end{tabular}

Number of observations: 1625 , number of groups: 98 , adjusted $R^{2}$ : 0.02

The table reports the estimation results of a panel regression with subject fixed effects. The dependent variable is effort. The standard errors are heteroskedasticity-robust $(\mathrm{HC} 1)$ and clustered on the subject level
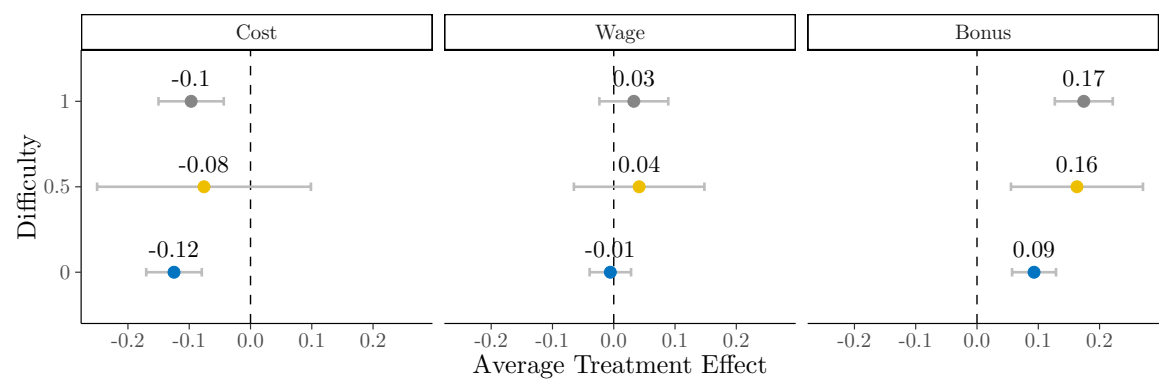

Note: The figure plots the ATEs of cost, wage, and bonus computed at different values of difficulty. The vertical bars represent $95 \%$ confidence intervals from a $t$-test.

Fig. 4 ATEs Conditional on Difficulty

where $\psi>0, \alpha>0$. I also assume that $v$ takes the standard constant relative risk aversion (CRRA) form, with $\beta_{u}=\gamma$

$$
v\left(x \mid \beta_{u}\right)=\frac{x^{1-\gamma}-1}{1-\gamma} .
$$

I estimate a representative agent model on the pooled data and use $i$ to index individual observations. In each observation $i$, effort is assumed to be chosen to maximize $U\left(a \mid \delta_{i}, \beta\right)$, where $\delta_{i}$ is an observed vector of treatment variables, which in the present case is an equivalent of regressors in a reduced-form model, $\beta$ is an unobserved vector of preference parameters, to be estimated, and effort $a$ is the outcome variable. The optimal effort as a function of the treatment variables vector $\delta$ and the preference parameter vector $\beta$ is denoted $a^{*}(\delta, \beta)$. No closed-form expression for $a^{*}(\delta, \beta)$ exists a model specification given by (8), (9), and (10), therefore, I rely on a numerical solution for optimal effort. I assume that the observed effort follows 


$$
a_{i}=a^{*}\left(\delta_{i}, \beta\right)+\epsilon_{i},
$$

where $\epsilon_{i}$ is a mean-zero error term. To estimate the model, I use a non-linear least squares estimator, ${ }^{24}$ which minimizes the sum of squared deviations between the observed and predicted choices:

$$
\hat{\beta}=\underset{\beta}{\arg \min } \sum_{i=1}^{N}\left(a_{i}-a^{*}\left(\delta_{i}, \beta\right)\right)^{2} .
$$

The risk-neutral parameter vector $\beta=(0,1,1)$ is used as a starting value.

\subsubsection{Estimation results}

Table 4 presents the estimation results. The estimates show that subjects are moderately risk averse in terms of the contribution of the curvature of the utility function to risk aversion. This finding is consistent with the previous findings in the laboratory experiments (Holt and Laury 2002; Andersen et al. 2008), however the estimate for the CRRA parameter is higher than is typically reported for binary lottery choices (Harrison and Rutström 2008)[P. 121]. The 95\% confidence interval for $\gamma$ covers the value of one, which implies a special case of a logarithmic utility.

The estimate of $\alpha$, which determines the shape of the probability weighting function, is significantly greater than one and leads to an S-shaped probability weighting. The S-shaped probability weighting implies likelihood sensitivity: subjects underweight the likelihoods of rare outcomes. As highlighted by the theoretical analysis in Sect. 4, such a shape arises precisely to fit the inverse-U pattern of effort response to difficulty that is observed in the data. The estimate of the scale parameter $\psi$ is different from 1, which implies that the probability weighting function crosses the diagonal at a point other than 1/e. Specifically, when $\psi \neq 1$ the crossing point is $\exp \left(-\psi^{\frac{1}{1-\alpha}}\right)$, which for the given estimates yields a value of $\approx 0.25$.

Figure 5 (left panel) shows the estimated probability weighting function, $\omega\left(p \mid \hat{\beta}_{\omega}\right)=\exp \left(-\hat{\psi}(-\ln p)^{\hat{\alpha}}\right)$. The underweighting occurs for probabilities approximately less than 0.25 . Probabilities greater than 0.25 are overweighted. The right panel of Fig. 5 shows the implied decision weights from the estimated probability weighting function. The decision weights are computed using equiprobable lotteries with different number of outcomes (two, three, or four). ${ }^{25}$ The picture shows that extreme outcomes are underweighted when there are more than two outcomes, and the worst (best) outcome is underweighted (overweighted) when there are exactly two outcomes.

\footnotetext{
24 One could estimate the model using Maximum Likelihood estimator (MLE).

25 Under probability weighting, the decisions weights are equivalent to outcome probabilities in EU model. However, to compute the decision weights one cannot simply transform the outcome probabilities using the probability weighting function, except for the two-outcome case. Using equiprobable lotteries with varying number of outcomes is a useful technique for showing the effect of probability weighting.
} 
Table 4 Estimates of the model with Probability Weighting

\begin{tabular}{lllll}
\hline Parameter & Estimate & SE & $2.5 \%$ & $97.5 \%$ \\
\hline$\gamma$ & 0.978 & 0.117 & 0.748 & 1.208 \\
$\alpha$ & 1.603 & 0.071 & 1.464 & 1.743 \\
$\psi$ & 0.821 & 0.054 & 0.716 & 0.926 \\
\hline
\end{tabular}

$\mathrm{N}$ obs $=1625$

The table reports the estimation results of the model specified in Eqs. (8), (9), and (10). The table reports the point estimates, standard errors, as well as $95 \%$ confidence intervals. The estimated parameters are the risk aversion $(\gamma)$, the shape parameter of the probability weighting function $(\alpha)$, and the scale parameter of probability weighting function $(\psi)$

The estimated shape of the weighting function is in stark contrast with some of the previous estimates (Wu and Gonzalez 1996; Bruhin et al. 2010; l'Haridon and Vieider 2019) that report an inverse-S shaped probability weighting function first proposed by Kahneman and Tversky (1979). ${ }^{26}$ While an inverse-S-shaped weighting function leads to overweigthing of small probabilities, I find underweighting of small probabilities. Interestingly, underweighting of small probabilities in a labor context was reported recently by DellaVigna and Pope (2018) who find that subjects significantly underweight a $1 \%$ chance of winning the prize. Their estimates indicate that subjects perceive $1 \%$ as $0.2-0.38 \%$, depending on the estimated model. My estimates, however, imply a more extreme underweighting: a $1 \%$ chance of receiving a prize is perceived as only $0.007 \%$. The present results are also related to the results reported by Wilcox (2015b) in a lottery-choice context. The study finds that the second most common type of probability weighting (after the concave shape) is also S-shaped.

Figure 6 compares the predicted effort, $\hat{a}_{i} \equiv a^{*}\left(\delta_{i}, \hat{\beta}\right)$, from the estimated model, specified in Eqs. (8), (9), and (10), to the actual effort, $a_{i}$, split by treatment variable. The figure shows that the estimated model reproduces the comparative statics found in the data reasonably well. ${ }^{27}$ In particular, the model does capture the inverse-U pattern of effort response to difficulty. It over-predicts, however, the mean effort for $\theta=0.75$ leading to a more prolonged increase in effort as difficulty increases and a sharper drop in effort when difficulty changes from 0.75 to 1 . The estimated model generates somewhat larger changes in effort in response to changes in wage, bonus, and cost than observed in the data.

\footnotetext{
${ }^{26}$ Also see a meta-analysis of probability weighting estimates in DellaVigna and Pope (2018)[Online Appendix Table 3].

27 As noted previously, the inverse-U treatment effect of difficulty on effort suggests that the model with probability weighting is a more suitable model for estimation, as opposed to EU model, which cannot generate such an effect. Figure D.4 in Appendix D.1 illustrates this point by plotting the predicted vs. actual mean effort levels from an estimated EU model. The estimated EU model has just one parameter, risk aversion. The figure shows that while the EU model is capable of capturing the treatment effects of the monetary variables on effort, it completely fails at reproducing the effect of difficulty. In fact, the estimated model predicts an increasing pattern of effort response to difficulty due to the fact that the estimated risk aversion parameter is negative $(-2.026)$.
} 

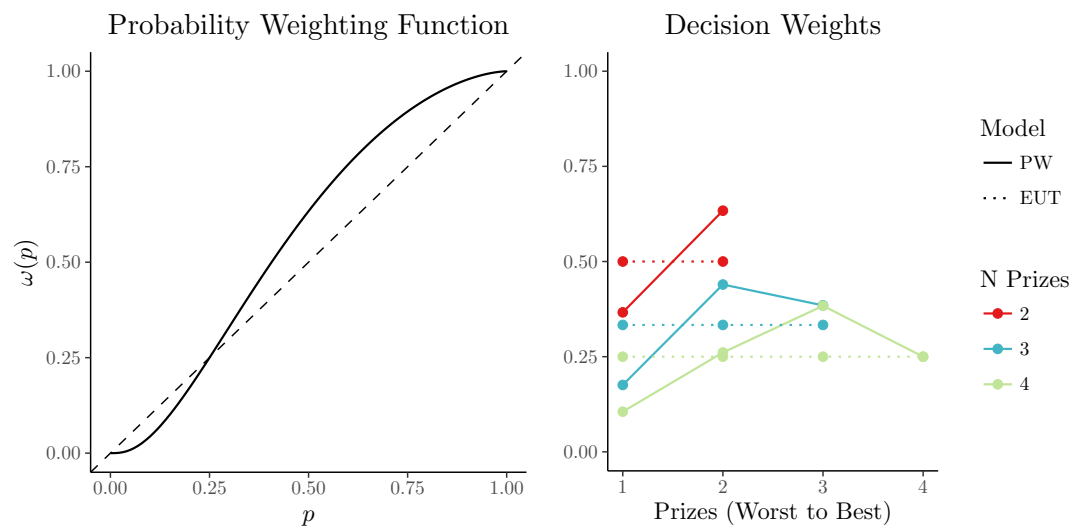

Notes: The left panel shows the estimated probability weighting function (solid line) together with 45-degree line (dashed) that represents the case of no weighting (as in EU model). The right panel shows the implied decision weights (solid lines) from the estimated probability weighting function for equiprobable lotteries with a varying number of outcomes $(2,3,4)$. The dashed lines show the corresponding decision weights for EU model, which are simply the outcome probabilities $(1 / 2,1 / 3,1 / 4)$.

Fig. 5 Estimated probability weighting function and implied decision weights

\subsection{Alternative explanations}

Is it possible that the observed inverse-U pattern of effort response to difficulty is generated via a mechanism other than probability weighting? To consider this possibility, one has to re-examine the comparative statics result (5). The result shows that the effect of difficulty on effort is determined by the signs of the two crosspartial derivatives, $u_{y a}$ and $p_{a \theta}{ }^{28}$ Consider first the cross-partial derivative of the utility function, $u_{y a}$. In the experiment, the cost of effort is induced to be monetary, hence the utility function can be written as $u(y, a)=v(y-c(a))$. The cross-partial derivative is then given by $-c^{\prime} v^{\prime \prime}$. Assuming risk-aversion, the sign of this derivative is positive.

Suppose, however, that subjects somehow misinterpret the cost of effort function or have a non-standard utility function. Even if subjects perceive the cost function to be $\tilde{c}(a)$ instead of the induced $c(a)=k a^{2}$, this would not change the result since it is unlikely that the perceived cost function would ever be decreasing. Subjects could clearly observe that higher effort resulted in more, rather than less, costs. Moreover, the first-derivative of $\tilde{c}$ would need to change its sign with difficulty to generate a non-monotonic effect of difficulty, which again is unlikely in the present design.

Suppose, on the other hand, that subjects' utility-of-money function $v$ is nonconcave. A convex function $v$ (i.e., risk-loving) would result in a positive crosspartial derivative and a monotonically increasing response to difficulty, not the observed inverse-U response. The utility-of-money function can be even more complex. For example, it can be convex for outcomes below a certain reference

$\overline{28}$ The signs of the remaining terms, $z, U^{\prime \prime}, p_{\theta}$, and $u_{y}$ are unambiguous. 


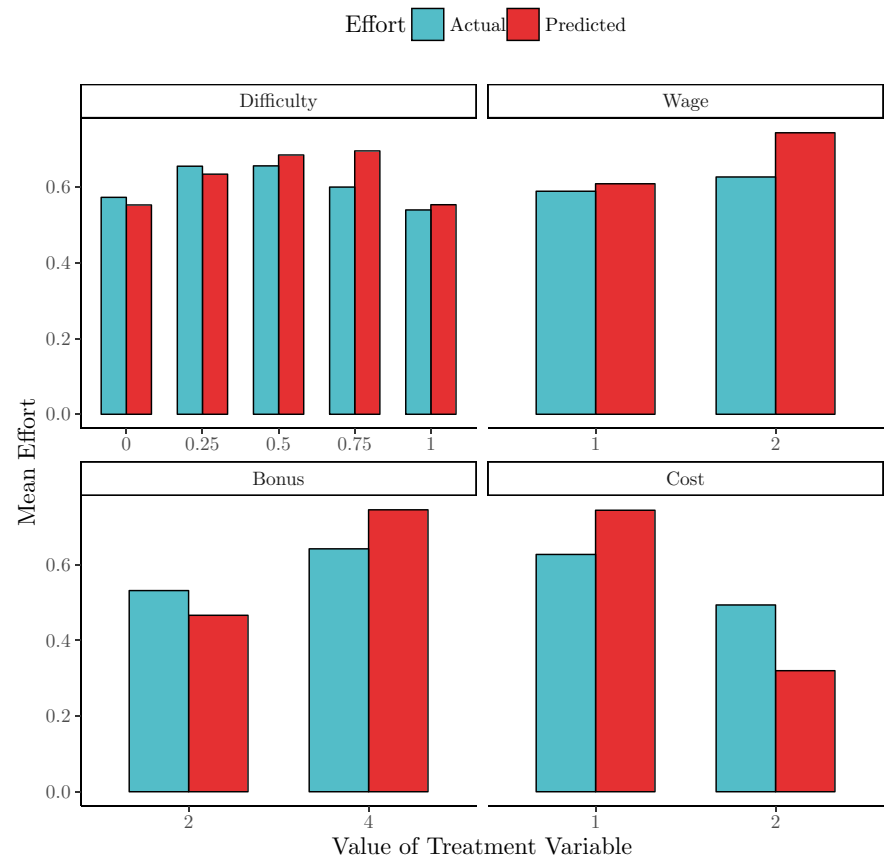

Note: The figure plots actual mean effort and mean effort predicted from the estimated RDU model by treatment variable.

Fig. 6 Actual and predicted mean effort levels

point and concave for outcomes above the reference point, resulting in an S shape as in the CPT value function (Tversky and Kahneman 1992). In this case the second derivative of $v$ would change its sign, and hence, the effect of difficulty would vary: difficulty would have a positive effect on effort for relatively low monetary outcomes and a negative effect for relatively high monetary outcomes. Note, however, that the sign of the effect of difficulty would not vary with difficulty itself. The implication of this alternative assumption is that the observed nonmonotonic effect of difficulty is actually confounded with the effect of monetary rewards. In this case the low-difficulty treatments should have been administered for low monetary rewards and the high-difficulty treatments should have been administered for high monetary rewards. This is impossible in the present design since the values of difficulty and monetary rewards were assigned independently. The distribution of observations between $\theta=0$ and $\theta=1(50 / 50)$ is exactly the same for low and high values of $w$ and for low and high values of $z$. Figure D.3 in Appendix D.1 further rejects the assumption of an S-shaped function $v$ by showing that the inverse- $U$ effect of difficulty is observed both for low and high levels of monetary outcomes.

Consider next the cross-partial derivative of the probability of success function, $p_{a \theta}$. The probability of success function is induced to be linear, hence, its 
cross-partial derivative is zero. ${ }^{29}$ This leaves us with the only possibility that subjects perceive the probability of success to be $\tilde{p}$ instead of $p$, i.e., they must use probability weighting. ${ }^{30}$

\section{Conclusion}

Research in labor economics has traditionally focused on monetary rewards as the primary incentive tool for principals to incentivize agents. Research in behavioral economics shows that monetary rewards are subject to psychological factors and that alternative behavioral incentives are also relevant for building incentive schemes for agents. I contribute to this strand of behavioral economics by drawing upon the insights of a prominent psychological theory of motivation, motivational intensity theory. Motivational intensity theory argues that the primary determinant of effort is task difficulty.

I study the effect of task difficulty and monetary rewards on effort in an incentivized experiment. I find that difficulty has an inverse-U effect on effort: effort first increases as difficulty goes up, reaches a peak, and then drops as difficulty continues to increase. The magnitude of the incentive effect of difficulty is on par with the magnitude of the incentive effect of conditional monetary rewards. Difficulty mediates the effect of monetary rewards: conditional rewards are most effective at inducing effort when task difficulty is intermediate or high.

The benefit of the present design is that it allows for a clean test of a particular mechanism behind the effect of task difficulty on effort: probability weighting. It is possible that in natural work environments the effect of difficulty on effort works through various other mechanisms, such as choking under pressure (Ariely et al. 2009; Hickman and Metz 2015). Likewise, it is possible that in the present chosen effort framework subjects are learning to optimize a model, and that the response to difficulty in a real effort framework, in which the probability of success function is not induced, would be different and, in particular, depend on subjects' ability. It is of interest, therefore, to investigate these alternative potential mechanisms and frameworks, as well as their interaction with the proposed mechanism, in future studies.

The structural estimates of the model yield an S-shaped probability weighting function. These estimates are different from the estimates in previous studies, which typically find an inverse-S-shaped probability weighting function. The first possible explanation for such a difference is that the present experiment is framed in a labor context, while previous studies typically used an abstract lottery context. Contextual instructions can affect subjects' behavior, as is evident from a variety of studies (Harrison and List 2004; Alekseev et al. 2017). This explanation is consistent with the recent evidence in DellaVigna and Pope (2018) who report underweighting of

\footnotetext{
${ }^{29}$ In naturally occurring settings, of course, the probability of success function could have a non-zero cross-partial derivative that would change its sign with difficulty.

${ }^{30}$ It is possible that subjects use some alternative heuristics for choosing effort that somehow result in the observed inverse- $U$ relationship between effort and difficulty. The discussion of such heuristics, however, would go outside of the scope of the utility maximization framework.
} 
small probabilities in a field experiment on effort. However, this explanation raises the follow-up question that would deserve further investigation: what features of a labor context make it different from an abstract context.

Another difference between the present study and previous studies on lottery tasks is the frequency of feedback. In the effort task, the feedback is provided every round, while in the lottery tasks, the feedback is typically provided only after all the choices are made. Experimental evidence suggests that providing frequent feedback can make subjects more sensitive to probabilities. Frequent feedback has been shown to result in linear probability weighting (Van de Kuilen 2009), or even in S-shaped probability weighting (Hertwig et al. 2004; Hertwig and Erev 2009) in a binary lottery choice setting.

The present findings are relevant for the design of optimal incentive schemes for workers and modeling effort. The strong incentive effect of difficulty calls for taking it into account when assigning tasks to workers. A manager can expect that it will take workers more effort to complete a moderately hard task than an easy task. However, a very hard task might not be devoted as much effort as desired. ${ }^{31}$ This behavioral response amplifies the direct negative effect of difficulty and thus can substantially lower a worker's performance. A principal can counter this detrimental behavioral effect of difficulty using conditional rewards since they are found to be most effective when difficulty is high. From a theoretical perspective, my results suggest that supplementing the workhorse model of effort with probability weighting can better explain certain patterns of effort provision and yield higher predictive power. From a methodological perspective, the present results suggest that experimental designs should control for difficulty to avoid confounding and that researchers can exploit the interaction between task difficulty and incentives to avoid a "ceiling-effect" problem.

Supplementary Information The online version supplementary material available at https://doi.org/10. 1007/s10683-021-09709-8.

Funding Open Access funding enabled and organized by Projekt DEAL.

Open Access This article is licensed under a Creative Commons Attribution 4.0 International License, which permits use, sharing, adaptation, distribution and reproduction in any medium or format, as long as you give appropriate credit to the original author(s) and the source, provide a link to the Creative Commons licence, and indicate if changes were made. The images or other third party material in this article are included in the article's Creative Commons licence, unless indicated otherwise in a credit line to the material. If material is not included in the article's Creative Commons licence and your intended use is not permitted by statutory regulation or exceeds the permitted use, you will need to obtain permission directly from the copyright holder. To view a copy of this licence, visit http://creativecommons.org/licen ses/by/4.0/.

\footnotetext{
31 While this is true for most subjects in this experiment, one has to be mindful about possible heterogeneity in responses, especially between males and females.
} 


\section{References}

Abeler, J., Altmann, S., Kube, S., \& Wibral, M. (2010). Gift exchange and workers' fairness concerns: When equality is unfair. Journal of the European Economic Association, 8, 1299-1324.

Abeler, J., Falk, A., Goette, L., \& Huffman, D. (2011). Reference points and effort provision. American Economic Review, 101, 470-92.

Alekseev, A., Charness, G., \& Gneezy, U. (2017). Experimental methods: When and why contextual instructions are important. Journal of Economic Behavior \& Organization, 134, 48-59.

Alter, A. L., Oppenheimer, D. M., Epley, N., \& Eyre, R. N. (2007). Overcoming intuition: Metacognitive difficulty activates analytic reasoning. Journal of Experimental Psychology: General, 136, 569-576.

Andersen, S., Harrison, G. W., Lau, M. I., \& Rutström, E. E. (2008). Eliciting risk and time preferences. Econometrica, 76, 583-618.

Ariely, D., Gneezy, U., Loewenstein, G., \& Mazar, N. (2009). Large stakes and big mistakes. Review of Economic Studies, 76, 451-469.

Ballinger, T. P., \& Wilcox, N. T. (1997). Decisions, error and heterogeneity. Economic Journal, 107, 1090-1105.

Balzer, W. K., Doherty, M. E., \& O'Connor, R. (1989). Effects of cognitive feedback on performance. Psychological Bulletin, 106, 410.

Benjamini, Y., \& Hochberg, Y. (1995). Controlling the false discovery rate: A practical and powerful approach to multiple testing. Journal of the Royal Statistical Society Series B (Methodological), 57, 289-300.

Blanes i Vidal, J., \& Nossol, M. (2011). Tournaments without prizes: Evidence from personnel records. Management Science, 57, 1721-1736.

Brehm, J. W., \& Self, E. A. (1989). The intensity of motivation. Annual Review of Psychology, 40, $109-131$.

Bremzen, A., Khokhlova, E., Suvorov, A., \& Van de Ven, J. (2015). Bad news: An experimental study on the informational effects of rewards. Review of Economics and Statistics, 97, 55-70.

Brinkmann, K., \& Gendolla, G. H. (2008). Does depression interfere with effort mobilization? Effects of dysphoria and task difficulty on cardiovascular response. Journal of Personality and Social Psychology, 94, 146-157.

Brockner, J., Grover, S., Reed, T. F., \& Dewitt, R. L. (1992). Layoffs, job insecurity, and survivors' work effort: Evidence of an inverted-U relationship. Academy of Management Journal, 35, 413-425.

Brouwer, A. M., Hogervorst, M. A., Holewijn, M., \& van Erp, J. B. (2014). Evidence for effects of task difficulty but not learning on neurophysiological variables associated with effort. International Journal of Psychophysiology, 93, 242-252.

Brüggen, A., \& Strobel, M. (2007). Real effort versus chosen effort in experiments. Economics Letters, 96, 232-236.

Bruhin, A., Fehr-Duda, H., \& Epper, T. (2010). Risk and rationality: Uncovering heterogeneity in probability distortion. Econometrica, 78, 1375-1412.

Bull, C., Schotter, A., \& Weigelt, K. (1987). Tournaments and piece rates: An experimental study. Journal of Political Economy, 95, 1-33.

Camerer, C. F. (1989). An experimental test of several generalized utility theories. Journal of Risk and Uncertainty, 2, 61-104.

Campbell, D. J., \& Ilgen, D. R. (1976). Additive effects of task difficulty and goal setting on subsequent task performance. Journal of Applied Psychology, 61, 319.

Capa, R. L., Audiffren, M., \& Ragot, S. (2008). The interactive effect of achievement motivation and task difficulty on mental effort. International Journal of Psychophysiology, 70, 144-150.

Cassar, L., \& Meier, S. (2018). Nonmonetary incentives and the implications of work as a source of meaning. Journal of Economic Perspectives, 32(3), 215-38.

Charness, G., Cobo-Reyes, R., Jiménez, N., Lacomba, J. A., \& Lagos, F. (2012). The hidden advantage of delegation: Pareto improvements in a gift exchange game. American Economic Review, 102, $2358-79$.

Charness, G., Gneezy, U., \& Kuhn, M. A. (2012). Experimental methods: Between-subject and withinsubject design. Journal of Economic Behavior \& Organization, 81, 1-8.

Cohn, A., Fehr, E., \& Goette, L. (2014). Fair wages and effort provision: Combining evidence from a choice experiment and a field experiment. Management Science, 61, 1777-1794. 
Corgnet, B., Gómez-Miñambres, J., \& Hernán-González, R. (2015). Goal setting and monetary incentives: When large stakes are not enough. Management Science, 61, 2926-2944.

Corgnet, B., Gómez-Miñambres, J., \& Hernán-González, R. (2018). Goal setting in the principal-agent model: Weak incentives for strong performance. Games and Economic Behavior, 109, 311-326.

Cox, J. C., Sadiraj, V., \& Schmidt, U. (2015). Paradoxes and mechanisms for choice under risk. Experimental Economics, 18, 215-250.

de Quidt, J., Haushofer, J., \& Roth, C. (2018). Measuring and bounding experimenter demand. American Economic Review, 108, 3266-3302.

Dechenaux, E., Kovenock, D., \& Sheremeta, R. M. (2015). A survey of experimental research on contests, all-pay auctions and tournaments. Experimental Economics, 18, 609-669.

DellaVigna, S., \& Pope, D. (2018). What motivates effort? Evidence and expert forecasts. The Review of Economic Studies, 85, 1029-1069.

Ely, J. C., \& Szydlowski, M. (2020). Moving the goalposts. Journal of Political Economy, 128, 468-506.

Fehr, E., Gächter, S., \& Kirchsteiger, G. (1997). Reciprocity as a contract enforcement device: Experimental evidence. Econometrica, 65, 833-860.

Fischbacher, U. (2007). z-Tree: Zurich toolbox for ready-made economic experiments. Experimental Economics, 10, 171-178.

Gächter, S., Huang, L., \& Sefton, M. (2016). Combining real effort with induced effort costs: The ballcatching task. Experimental economics, 19, 687-712.

Gendolla, G. H., \& Richter, M. (2005). Ego involvement and effort: Cardiovascular, electrodermal, and performance effects. Psychophysiology, 42, 595-603.

Gendolla, G. H., Richter, M., \& Silvia, P. J. (2008). Self-focus and task difficulty effects on effort-related cardiovascular reactivity. Psychophysiology, 45, 653-662.

Gendolla, G. H., Wright, R. A., \& Richter, M. (2012). Effort intensity: Some insights from the cardiovascular system. In R Ryan (Ed.), The Oxford handbook of human motivation, Oxford University Press, Oxford, pp. 420-438.

Gill, D., \& Prowse, V. (2012). A structural analysis of disappointment aversion in a real effort competition. American Economic Review, 102, 469-503.

Gneezy, U., \& List, J. A. (2006). Putting behavioral economics to work: Testing for gift exchange in labor markets using field experiments. Econometrica, 74, 1365-1384.

Gneezy, U., Meier, S., \& Rey-Biel, P. (2011). When and why incentives (don't) work to modify behavior. Journal of Economic Perspectives, 25(4), 191-209.

Gneezy, U., \& Rustichini, A. (2000). Pay enough or don't pay at all. Quarterly Journal of Economics, $115,791-810$.

Goerg, S. J., \& Kube, S. (2012). Goals (th)at work. Working Paper No. Bonn 2012/19, Max Planck Institute for Research on Collective Goods.

Goerg, S. J., Kube, S., \& Radbruch, J. (2019). the effectiveness of incentive schemes in the presence of implicit effort costs.' Management Science.

Gómez-Miñambres, J. (2012). Motivation through goal setting. Journal of Economic Psychology, 33, 1223-1239.

Gul, F., Natenzon, P., \& Pesendorfer, W. (2014). Random choice as behavioral optimization. Econometrica, 82, 1873-1912.

Harrison, G. W., \& List, J. A. (2004). Field experiments. Journal of Economic Literature, 42, 1009-1055.

Harrison, G. W., \& Rutström, E. E. (2008). Risk aversion in the laboratory. Bingley, UK: Emerald, Research in Experimental Economics, Volume 12, In JC Cox and GW Harrison (eds.), Risk aversion in experiments.

Harrison, G. W., \& Swarthout, J. T. (2014). Experimental payment protocols and the bipolar behaviorist. Theory and Decision, 77, 423-438.

Heath, C., Larrick, R. P., \& Wu, G. (1999). Goals as reference points. Cognitive Psychology, 38, 79-109.

Hennig-Schmidt, H., Sadrieh, A., \& Rockenbach, B. (2010). In search of workers' real effort reciprocity: A field and a laboratory experiment. Journal of the European Economic Association, 8, 817-837.

Hertwig, R., Barron, G., Weber, E. U., \& Erev, I. (2004). Decisions from experience and the effect of rare events in risky choice. Psychological Science, 15, 534-539.

Hertwig, R., \& Erev, I. (2009). The description-experience gap in risky choice. Trends in Cognitive Sciences, 13, 517-523.

Hickman, D. C., \& Metz, N. E. (2015). The impact of pressure on performance: Evidence from the Pga tour. Journal of Economic Behavior \& Organization, 116, 319-330. 
Hoch, S. J., \& Loewenstein, G. F. (1989). Outcome feedback: Hindsight and information. Journal of Experimental Psychology: Learning, Memory, and Cognition, 15, 605.

Holmström, B. (2017). Pay for performance and beyond. American Economic Review, 107, 1753-1777.

Holt, C. A., \& Laury, S. K. (2002). Risk aversion and incentive effects. American Economic Review, 92, 1644-1655.

Hossain, T., \& List, J. (2012). The Behavioralist visits the factory: Increasing productivity using simple framing manipulations. Management Science, 58, 2151-2167.

Hsiao, Y. C., Kemp, S., \& Servátka, M. (2019). On the importance of context in sequential search. In Working paper, Macquarie Graduate School of Management.

Jayaraman, R., Ray, D., \& de Vèricourt, F. (2016). Anatomy of a contract change. American Economic Review, 106, 316-58.

Kahneman, D., \& Tversky, A. (1979). Prospect theory: An analysis of decision under risk. Econometrica, 47, 263-291.

Labroo, A. A., \& Kim, S. (2009). The 'instrumentality' heuristic why metacognitive difficulty is desirable during goal pursuit. Psychological Science, 20, 127-134.

Laffont, J. J., \& Martimort, D. (2009). The theory of incentives: The principal-agent model. Princeton: Princeton University Press.

LaGory, J., Dearen, B. B., Tebo, K., \& Wright, R. A. (2011). Reported fatigue, difficulty, and cardiovascular response to an auditory mental arithmetic challenge. International Journal of Psychophysiology, 81, 91-98.

Latham, G. P., Seijts, G., \& Crim, D. (2008). The effects of learning goal difficulty level and cognitive ability on performance. Canadian Journal of Behavioural Science, 40, 220-229.

Lazear, E. P. (2018). Compensation and incentives in the workplace. Journal of Economic Perspectives, 32(3), 195-214.

Lazear, E. P. (2000). Performance pay and productivity. American Economic Review, 90, 1346-1361.

1'Haridon, O., \& Vieider, F. M. (2019). All over the map: A worldwide comparison of risk preferences. Quantitative Economics, 10, 185-215.

Luce, R. D. (1959). Individual choice behavior: A theoretical analysis. New York: Wiley.

Matêjka, F., \& McKay, A. (2015). Rational inattention to discrete choices: A new foundation for the multinomial logit model. American Economic Review, 105, 272-98.

McDaniel, T. M., \& Rutström, E. E. (2001). Decision making costs and problem solving performance. Experimental Economics, 4, 145-161.

Mirrlees, J. A. (1971). An exploration in the theory of optimum income taxation. The Review of Economic Studies, 38, 175-208.

Prelec, D. (1998). The probability weighting function. Econometrica, 66, 497-528.

Quiggin, J. (1982). A theory of anticipated utility. Journal of Economic Behavior \& Organization, 3, $323-343$.

Richter, M. (2015). Goal pursuit and energy conservation: Energy investment increases with task demand but does not equal it. Motivation and Emotion, 39, 25-33.

Richter, M., Friedrich, A., \& Gendolla, G. H. (2008). Task difficulty effects on cardiac activity. Psychophysiology, 45, 869-875.

Silvestrini, N., \& Gendolla, G. H. (2009). The joint effect of mood, task valence, and task difficulty on effort-related cardiovascular response and facial EMG. International Journal of Psychophysiology, 73, 226-234.

Silvestrini, N., \& Gendolla, G. H. (2011). Masked affective stimuli moderate task difficulty effects on effort-related cardiovascular response. Psychophysiology, 48, 1157-1164.

Smith, T. W., Baldwin, M., \& Christensen, A. J. (1990). Interpersonal influence as active coping: Effects of task difficulty on cardiovascular reactivity. Psychophysiology, 27, 429-437.

Smithers, S. (2015). Goals, motivation and gender. Economics Letters, 131, 75-77.

Starmer, C., \& Sugden, R. (1989). Probability and juxtaposition effects: An experimental investigation of the common ratio effect. Journal of Risk and Uncertainty, 2, 159-78.

Sternberg, S. (1966). High-speed scanning in human memory. Science, 153, 652-654.

Stott, H. P. (2006). Cumulative prospect theory's functional menagerie. Journal of Risk and Uncertainty, $32,101-130$.

Tversky, A., \& Kahneman, D. (1992). Advances in prospect theory: Cumulative representation of uncertainty. Journal of Risk and Uncertainty, 5, 297-323.

Van de Kuilen, G. (2009). Subjective probability weighting and the discovered preference hypothesis. Theory and Decision, 67, 1-22. 
Vandegrift, D., \& Brown, P. (2003). Task difficulty, incentive effects, and the selection of high-variance strategies: An experimental examination of tournament behavior. Labour Economics, 10, 481-497.

Wilcox, N. T. (2015a). Error and generalization in discrete choice under risk. In Working paper, Chapman University.

Wilcox, N. T. (2015b). Unusual estimates of probability weighting functions. In Working paper, Chapman University.

World Bank Group. (2015). World development report 2015: Mind, society, and behavior. Washington, DC: World Bank.

Wright, R. A. (1996). Brehm's theory of motivation as a model of effort and cardiovascular response.' In P. M. Gollwitzer and J. A. Bargh (Eds.), The psychology of action: Linking cognition and motivation to behavior, Guilford Press, pp. 424-453.

Wright, R. A. (1984). Motivation, anxiety, and the difficulty of avoidant control. Journal of Personality and Social Psychology, 46, 1376.

Wright, R. A., Contrada, R. J., \& Patane, M. J. (1986). Task difficulty, cardiovascular response, and the magnitude of goal valence. Journal of Personality and Social Psychology, 51, 837.

Wu, G., \& Gonzalez, R. (1996). Curvature of the probability weighting function. Management Science, 42, 1676-1690.

Publisher's Note Springer Nature remains neutral with regard to jurisdictional claims in published maps and institutional affiliations. 